\title{
Methodological Choice and the Study of Sensitive Issues
}

\section{Defining My Concern}

There has been relatively little concern with methodological issues within the study of religion, as compared with, for example, social or medical sciences, or somewhat surprisingly even with general history as maintained by Sjöblom (1999). The most obvious reason for this is in a tradition following on from a general resistance to what has, within the field, been labeled reductionistic views. Not infrequently has the need for theoretical and/or methodological refinement been neglected as unnecessary as long as the researcher knows - that is thoroughly knows - the facts of his or her subject theme. If one excepts the requirement that one should master a sacred language, researchers within the field have been acknowledged according to their expertise within a certain world religion - more specifically knowledge of its normative texts - rather than their methodological competence.

Another reason for this prolonged state of affairs (i.e. neglect of methodological issues) might be found in the inter-disciplinarian nature of the subject theme. The study of religion could well be compared to other overall umbrella-like or thematically organized subjects such as women's studies or minority and refugee studies, which are my own second field of interest. When so little is shared among scholars of different persuasions, except for the subject theme, the situation offers many benefits - like getting a fuller view from different angles or contrasting findings gained by diverse methods but it also poses a range of difficult issues - not the least of a methodological kind - which are perhaps easiest to avoid. Moreover, such a situation may invite unfortunate or half-hearted combinations of conflicting methodological approaches which are not very good by any scientific standards. For example, the widespread tendency to treat qualitative methods as if they were simply derived from quantitative ones - as a kind of miniature case (i.e. the one out of a hundred) may confuse more than solve the problems involved. 
This article has sprung out of such considerations. As I see it, there is a need for a continuing clarification of how diverse methodological approaches relate to the study of religion in general, and what is more, of certain aspects of the role of the researcher in particular. Since I myself have been educated within separate - dare I say opposed - scholarly traditions - and today hold the position not only of professor of the history of religion at the university of Trondheim but also professor of psychology at the university of Oslo, and that in the medical faculty - I saw a chance to contribute towards such a discussion here in Åbo.

Because of this professional background of mine I have chosen to relate to that part of our subject theme which collects its own empirical material in face to face interactional situations, such as through fieldwork, clinical assessments or by way of interviewing. While textual studies are thus outruled, I nevertheless believe that my reasoning has a certain relevance for them as well; that is, if one considers formulations prevalent among some scholars that appear to bridge the two concerns, i.e. of written vs. oral sources ${ }^{1}$. Such formulations that I have in mind may, for example, by reference to Ricoeur (1991) and others ${ }^{2}$ designate the person or research subject as a text to be read or religion and particularly ritual as a form of communicative language (Lawson and Cauley 1990, among others), or they may critically inquire about the motives of 'Those who write our history' (e.g. Bertaux 1991; Clifford and Marcus 1986).

\section{On Sensitive Research}

However, the study of religion is not only inter-disciplinarian in nature, but there is also an increasingly multicultural awareness within the field. Geertz (1999) refers to the ensuing concept of scienceitis or inclination towards self-scrutiny of the kind that brands all Western science as basically colonialist. While Wiebe (1999) further notes, how the present devaluation of neutral science, has, within the field of religious studies, come to prolong an approach which substitutes a mere understanding or, as I would add, an emic for an explanatory or etically derived analysis of religious phenomena.

\footnotetext{
${ }^{1}$ On the diversity of sources and territorial concerns within the subject area more generally see Pye 1999 and Thomassen 1999.

${ }^{2}$ Luckmann 1999 makes use of texts in this way.
} 
But what is more, time and again our subject theme turns out to be of a kind that could be labeled sensitive in nature as illustrated, for example, by my own research into Muslim female refugees (Ahlberg 1997). By sensitive research I mean studies which bear a potential risk of unwelcome social consequences or psychic costs for the participants or some social category that they may represent. For a closer scrutiny of the concept see Renzetti and Lee (1993: 3-13), who, among other things, distinguish between a broader definition denoting all somehow controversial studies which may have social implications for the subjects involved (i.e. almost any applied social research), and, more specifically, research which is, moreover, likely to become threatening for the parties involved.

It is perhaps enough here to remind the reader of the uneasy relationship between the study of Islam and the debate on Orientalism or human rights issues on the one hand (e.g. Lindholm 1992; an-Naim 1990; Ahlberg 1994), as well as the growing xenophobia directed at Third world migrants in many Western countries on the other (Shahid and Koningsveld 1991; Metcalf 1996). ${ }^{3}$ In addition to the kind of topics which touch on deviance and social control, Renzetti and Lee (1993: 6) add a few more that are likely to be perceived as sensitive. They are where research intrudes into the private sphere or some deeply personal experience, impinges on the vested interests of those in power or deals with things sacred to those who do not wish them profaned.

But what particular issues are considered sensitive naturally vary cross-culturally; and what is initially believed to be a sensitive issue thus might not be such after all. For example the registration of personal belief in the Scandinavian context has not been considered necessary, or even comme il faut with reference to its sensitive nature as it is believed - besides to be a highly personal experience and private issue - to touch upon racist issues. But in many countries from where the migrants come it is quite to the contrary considered the

${ }^{3}$ At present, national asylum policies within the European Common Market and associated countries like Norway, are in the process of being coordinated in order that what has by the critics been denoted as The Fortress Europe (i.e. to keep Third World foreigners out) will be erected around it. And those few Muslims who do manage to cross the borders, moreover, frequently have to endure the negative stereotypes prevalent among their Western hosts, which are nurtured by the emerging North-South enemy-constellation of the post-communist era, and, however unfairly, tend to equate them with their very oppressors. For a study of the confrontation of Muslim and Western interests in the area of immigration see Ahlberg 1990. 
first and foremost identificatory - that is collective - and quite unproblematic issue.

Research which at the outset may appear quite harmless can, likewise, later turn out to be potentially risky for its more or less unprepared practitioners. Such has been the case for several participants of an interdisciplinary seminar which I head at the Psychosocial Centre for Refugees (University of Oslo), for example, for a psychologist studying toddlers adopted from abroad who during her subsequent field contacts turned out to have been sexually abused by army personnel in their Latin-American orphanages prior to their adoption. Suddenly the image carried by the foster parents of their hard-won little Princesses were about to crack in an unforeseeable way, were this piece of information to become known. And her subsequent research involvement touching on the issue of trading with children has not made the situation more comfortable (Carli 1997). Likewise, a project by a Ph.D. student of mine in medical anthropology concerning the psycho-cultural adaptation of unaccompanied minor refugees form the Third World, has raised some initially quite unexpected issues connected to the more or less terrible secrets that they themselves may harbor concerning their (real) identities - such as having provided false age, name or familial relationships to the immigrant authorities (Harsløf-Hjelde 1996). A leakage of which kind of sensitive information, in the last instance, might threaten their very juridical status and thus protection in exile.

Yet another study by two psychology students of mine (Sinnes and Nilsen 1997) on preachers belonging in a religious revivalist movement of Northern Scandinavia and Finland, called Lestadianism, concerning their attitudes to mental health generally and the professionals working within the sector in particular, could provide another example. The movement at issue is characterized by a strong regional profile, frequently viewed as a sort of ethnicized version of Christianity intended for the Sami and the aboriginal Finnish immigrant or Kveni minority. Against the background of the overall political tensions concerning minority issues that prevail in its Northern Norw egian surroundings the results of this study may stay in danger of being dragged into the research external area of press sensational writing and/or being misused for political purposes. To the extent that the statistics may turn out to be of a sensitive nature, the same fortune could easily befall another Ph.D. supervisee of mine within psychology, who studies the relationship between externalizing (i.e. in this case criminal) and internalizing (i.e. as reflected in their mental health) coping strategies among youth of immigrant parents covering most of the said cohort in Oslo (Thorgersen 1997). 
It is not the topic in itself so much as its relationship to the social context in which the research is carried out, that is of importance here. And that brings me to the role of the researcher. In addition to those implications which apply to the (primary) vulnerability of the research subjects (who, as a rule, have not initiated the process themselves) - in my and many of the cases referred to above, for example, Third World migrants and adoptees, who might suffer stigmatization from focusing on the problematic aspects of their exile situation - sensitive research may be burdensome to the researcher as well. Because the former aspects - especially as concerns members of lower status and/or minority groups — are relatively more well-known although not always attended to (even in the literature on method), in this connection I will focus on the latter largely unacknowledged aspect of the problem. Despite the fact that the power within the subject-object relationship of the research setting itself largely belongs with the researcher, this is not so in respect of the surrounding research external (community) setting in which, for example, a researcher into deviant groups who rely on emic involvement and/or a human rights commitment might become viewed as more or less contaminated by the research topic him or herself ${ }^{4}$.

Research on sensitive issues thus raises a whole range of problematic issues of methodological relevance. It affects almost any stage in the research process rendering problematic the collecting, holding and/or dissemination of research data. And the problems that may arise from it in hindsight take many forms, such as political, ethical or legal, as well as those affecting the personal lives and security of its participants - researchers as well as subjects. All these considerations are worth serious academic pondering, not the least from the point of view of the choice of research method and design.

\section{Polarities of Methodological Approach: an Issue of Varying Inputs as Well as of Outputs}

The typological arrangement in Figure 1 contrasts with what could perhaps be labeled a Natural Science (NS) - and by extension medical - versus a Humanistic (HUM) Model - in which I include the social sciences as well. It is representative of a division which often - though not quite correctly - is equated with quantitative hard versus qualitative soft data approaches (Bryman 1992; Holter and

\footnotetext{
${ }^{4} \mathrm{Cpr}$. what is said on secondary traumatization below on page 25 .
} 
Kalleberg 1996; Yin 1984; Silverman 1989). Here I have registered certain main differences between the two approaches which are of relevance to my argumentation. They include - besides the disparities in viewing reality as indicated on top of the scheme - a restricted, or in the eyes of its critics inflexible, focus which demands a high level of precision or operationalization and offers few - if not only one single - opportunity for measurement and data collection, versus one which - quite to the contrary - - requires greater flexibility of performance.

Figure 1

\begin{tabular}{|ll|}
\hline \multicolumn{2}{c|}{ Polarities of Methodological Approach } \\
$\begin{array}{l}\text { (view of social reality } \\
\text { as external to actor) }\end{array}$ & $\begin{array}{l}\text { (view of reality as } \\
\text { socially constructed) }\end{array}$ \\
\hline $\begin{array}{l}\text { quantitative hard data } \\
\text { (restrictedly reliable) }\end{array}$ & $\begin{array}{l}\text { qualitative soft data } \\
\text { (contextually rich) }\end{array}$ \\
$\begin{array}{l}\text { sample generalization } \\
\text { (measurement/replication) }\end{array}$ & $\begin{array}{l}\text { content contextualization } \\
\text { (verstehen/interpretation) }\end{array}$ \\
$\begin{array}{l}\text { research assistancy } \\
\text { (reliability of instruments) }\end{array}$ & $\begin{array}{l}\text { researcher as participant medium } \\
\text { (education of observers) }\end{array}$ \\
$\begin{array}{l}\text { social survey/ } \\
\text { experimental design } \\
\text { (structured methods) }\end{array}$ & $\begin{array}{l}\text { unstructured interviews } \\
\text { participant observation/ } \\
\text { case study design }\end{array}$ \\
\hline
\end{tabular}

The latter approach gives many more opportunities for revision and contact, not only between the researcher and his or her research subjects but also between the theoretical analysis and collecting the empirical material. In the Natural science model these are viewed and thus methodologically protected - as highly separate operational units, which (by way of their very separateness) ensure or strengthen the validity of the analysis at issue. In this type of argumentation the researcher is supposed, first to formulate explicit propositions about the topic to be investigated and design the research in advance specifically to answer these questions and - note - nothing else (i.e. all else being considered irrelevant surplus or somehow disturbing data). This is why one is frequently cautioned not to change the focus of the enquiry during the process, as compared to the opposite view, which - quite to the contrary - may en- 
courage the researcher to take up, for example, someone's genealogy while simultaneously paying due attention to all the surplus material that may emerge in the very process 5 . In other words, starting your research somewhere (e.g. in shamanistic rituals) in order - somewhat unexpectedly - to end up almost anywhere else (perhaps in the sphere of economy).

As complementary or even competing views these different scientific approaches largely depend on a different kind of input; to the extent that the very disturbing factors (i.e. in terms of reliability) of the one approach (which are as a consequence ruled out as errors), may in fact be considered the very best material to ponder by the other; that is, a material that has emerged while taking $a$ closer look, and in the case of interviewing going beyond the mere research questions into considering their wider context.

While the Natural Science approach is modeled on the requirements of highly structured experimentation with the ideal of bringing the world out there into a controlled (i.e. closed) laboratory in mind, the latter model - derived from within the field of the $\mathrm{Hu}$ manities - venture the opposite way out there into the field, being among other things, built around participant observation in natura (i.e. under field conditions) with an accompanying flexibility of thought and action as in unstructured methods. And that is the very aspect that makes the latter type of approach better suited for attending to problems of the kind discussed in this article, because it is about an intensified attentiveness in relationship to the surroundings.

For example, in the field of refugee studies which more often than not implies dwelling on sensitive and controversial issues, participant observation and in-depth interviews come to represent important methods because they rely on a sustained and intensive interaction in the cause of which any additional and/or adverse problems to affect the subjects (especially from what they reveal in the interviewing situation) are more easily detected, as vulnerable interviewees are also hopefully protected (sometimes the mere knowledge that someone is attentive to your plight is helpful, the idea Amnesty rests on).

There is a further concern for the representativeness of the sample considering some wider population (i.e. generalization) within the NS model, for which purpose some precise measurement is chosen which

\footnotetext{
${ }^{5}$ This particular exercise was used by Peter G. Riviere at a Field methods course arranged by Refugee Studies Programme, Oxford University in 1994.
} 
comprises a large but minutely exact battery of input. The very wording of a question and the fact that it has been used before (i.e. standardized) - for example, cross-culturally in a wide variety of testing situation while remaining the same - seems more important than pondering its shades of meaning or relevance as a concept to those being asked to respond (i.e. as long as they do respond). This is, of course, in order to minimize errors which hamper the replicability of the research design and reach a statistically relevant outcome, again, in contrast to the unique processual features of much HUM research which is difficult to replicate at will. That is also why in the latter case (instead of instrumental precision and reliability) one goes for educating the researcher as a participant medium.

However, such differences in scientific outlook do not merely concern the issue of the scientific procedure itself or even its design (that is, structured versus unstructured arrangements) but, moreover, they turn on how the end product is construed when taken as a genre; for example when published as articles of few words and figures or extensive monographs punctuated by quotations and detailed description. Already the employment of certain scientific concepts like causal or independent variables, standardization, reliability or generalization, will impose expectations forewarning the reader about the material to come. Here, the researcher is counseled to study the levels of correlation between types of treatment and their effects through examining a large number of passively recipient cases (i.e. hypothesis-testing). But by adopting such advice he or she simultaneously avoids the detailed study of internal processes and activities of particular agents which bring these effects about, that are better attended to within HUM designs, in which case the researcher is also free to concentrate on whatever numbers are favorable from the point of view of his or hers theoretical interests, if it be one single case. The ideal end result constitutes some kind of contextualized protocol which excels in conceptual analysis and subjective relevance; is revealing of both the researcher and his or her research subjects, while documenting the process as well as its content.

Thus, the issue of research design is not only about different inputs, but one ends up in a differing output, that is style of presentation, as well. And, therefore, it is to a certain extent also about the criteria on which we base our evaluations, because the way of posing the problems as well as presenting the findings are so different. For example, the scholarly debates which have recently been going on in Norwegian academic circles (as reflected, for example, in Apollon 1997) concerning cheating in or the criteria for excellency of research, similarly touch upon the said divisions. This is because of the turn 
the exchange of views has taken, inasmuch as it is mostly concerned with technicalities of a kind that would be considered less relevant from the point of view of a humanistic concern which follows quite different scientific procedures. Such issues as whether the (everlonger) authors lists we encounter within the medical field of study correctly reflect the work load of its participants (i.e. when a monograph is frequently written by one single author alone), or say, the fabrication, stealing or altering of (i.e. numerical) results where testing or laboratory experiments are involved, seem irrelevant for those working within the opposite camp.

Given the complexities of contextualizing the findings within the humanistic approach it is more unlikely - though, of coarse, not impossible - that a researcher would go unnoticed for very long while busy fabricating the required comprehensive setting or whole story. The case of Carlos Castanedas $(1972 ; 1974 a ; 1974 b ; 1974 c ; 1977)$ series of publications from within the subject of anthropology, would be a rare example of the opposite; another would be the famous cover-up article by Alan Sokal Transgressing the Boundaries: Towards a Transformative Hermeneutics of Quantum Gravity published in the post modernist periodical Social Text (Sokal 1996), which the author after publication admitted to have written on purpose as part and parcel of what has been labeled an ongoing Science War between the two approaches.

\section{Some Problems of the Natural Science Approach}

If we let the prevalent criteria for research excellency derived from the Natural Science model, such as, say, concerning the frequency of publications on an international level, be our sole evaluative guide, we might - from the point of view of a HUM model - end up with a highly selective focus. The case of professor Dorothea Fosså, the medical scholar who tops the statistics at the university of Oslo, could highlight some aspects of the problem. In an interview (Syvertsen 1997) she herself grants the following facts about her research activities:

The work day of this mother of four starts at two o'clock in the night (as it has for ten years now, for how could she otherwise have managed). Then, from eight o'clock on in the morning she follows an ordinary hospital doctor's day while her two research assistants punch out the latest experimental data results; which she herself receives in the late afternoon before putting down an article, and delivering it at the doorstep of a translator who, again, returns it before 
midnight in order that our researcher may start another day doing the last check-up before posting her article off. And, she adds - we may assume somewhat mischievously - that her students are offered supervision at half past six in the morning.

I do not for a moment want to underestimate the obvious merits of the said scholar's astonishing working capacity nor the quality of her articles all published in international journals of the very best repute. What I do want to focus on, is a more general issue that the obvious pressures surrounding her research situation raise concerning the need for balancing between the requirements for quantity and quality for scholars of less energy. On how much we, in the name of science, demand from those - men and perhaps especially women working within the field at the expense of what could for the benefit of my argument be called the requirement of an ordinary life. The strategic retreat to certainty by way of restricting the focus of a scientific investigation, tends to sweep away - not only scientific errors - but its time-consuming imaginative underpinnings. Added the accompanying fast growing tempo in the frequency of publishing, the result may be a science which seems certain in a very restricted sense only, not frequently turned over in a cross-cultural or even historical context.

The problems encountered in the NS model are thus both of a structural and pragmatic kind. For one thing, the very conceptual starting point may be at odds with the particular reality under study, while, at the same time, its revision might be difficult because this type of design tends to treat any irregularities as irrelevant errors to be discarded. For example, the feasibility of using self-assessment scales like the Harward Trauma Questionnaire, widely used in psychiatric research and developed in the West, in a cross-cultural setting may be questionable already when considering the problems of translating the measurable concepts into some smaller language of a non-literate context. But, what is more, in the wrong hands the very way of implementing such a survey, may, in the eyes of the immense trauma focused on in this instrument and the accompanying emotionality involved (and presumably aroused) by the intervention itself, appears as - if not inhuman or unethical, at least often - a premature questioning or testing of helpless and hapless refugees.

Whenever we are to ask research questions which are not straightforward and simple to answer (i.e. restricted in the above sense) but

\footnotetext{
${ }^{6}$ While simultaneously ignoring - not only the classics - but frequently any publications much older than a few years.
} 
charged with subjective meaning for the objects of our research, or that are somehow considered as sensitive in nature, such a question in itself may, moreover, produce different answers at different points in time, because it initiates a process of reflection and afterthought. And, that is, without these different answers thereby necessarily being wrong or invalidated, to use a more scientific term, as they would be in a design built on the natural science model. For example, the straightforward asking of a tradition-oriented refugee patient whether (he or) she has been raped will almost certainly bring instant denial and accompanying attempts at keeping its possible occurrence a secret. This is also why non-western women generally do not seek help for the medical and psychological sequel of sexual violence. Instead they are referred for treatment for problems related to the trauma, such as diffuse gynaecological problems or suicidal gestures.

In one such case of my own, an illiterate Kurdish refugee woman herself did not even comprehend the torture she had experienced (i.e. in her case the electrical torture of her genitals) as such. This was since she had never visited a gynaecologist, which was what her somewhat unwilling torturer (himself perhaps forced to commit the atrocities?) was posing as, while claiming to burn away a cancerous tissue. And for all those years that had passed since the incidence (five of which were in exile) she has had no-one to ask (Ahlberg, 1997). The point from the perspective of religious studies is that sexual atrocities of this kind must be understood within their psychocultural and religious or regional context, as an issue regarding the proper place of women or what it means to be female. Thus, in due time, the same patient also reported how rebellious husbands were expelled as unbelieving kafirs by the local Iranian pasdaran revolutionary guardians who view their flight as synonymous with religious defection. The number of times a woman was raped in prison was, according to her personal (and very painful) experience, in direct proportion to the number of male relatives who were perceived as having fled their responsibilities as defenders of their wives' honor while (by way of their acts) leaving them unprotected.

Episodes of this kind, irrespective of any individual guilt, risk bringing the whole family into disrepute, which is why sexual violations remain underreported. And, therefore, why any one rehabilitative effort - not to speak of research interventions - which ignore this sensitive fact, especially if public revelations are involved, merely adds to the dilemma of those involved in this kind of suffering. The way of posing research questions is a frequently encountered problem in clinical research generally, and especially when it is, 
moreover, cross-cultural in nature, because the research tools commonly used have traditionally relied so heavily on diagnostic procedures and testing batteries developed in line with the NS model. As the counter-argument runs, such a model fails to take account of its appropriateness in studying people; i.e. for objectifying people without acknowledging the fact that - as opposed to natural phenomena - the research done may in fact come to affect them in decisive ways, a feature which, again, becomes especially highlighted when using face to face interview methods and, especially, when studying differences between people across cultures.

\section{Polarities of Subject-Object Interaction: on the Issue of Going Hunting for Data ${ }^{7}$ in Sensitive Research}

It is not my intention to dwell on the differences between diverse scientific models as such in this article, except for merely regretting the fact that, while issues of method have perhaps been undervalued in comparative religion, on the other hand, qualitative methods as largely resorted to in this subject, have frequently been unjustly treated in the social and medical sciences. The standard textbooks of these subjects exemplify a tendency to view qualitative methods as suited for some kind of restricted preliminary stage for developing hypotheses for a more proper quantitative study, while dwelling on the difficulties involved, if such a venture were to conform to a canon modeled on a NS approach. As a rule, the presentation of qualitative methods is confined to headings such as 'Some problems of...' and sandwiched within or appendiced to the main treatise.

\footnotetext{
${ }^{7}$ In a research seminar that recently took place at the university of Trondheim (Dept. for Comparative Religion 1997) Thomas Luckmann was lecturing under the heading Language - how to go hunting for data in social research. A main point of his was in discussing the limitations related to the kind of preproduced texts traditionally used within the social sciences as compared to the benefits of what he himself formulated as "Shooting the bird in flight" or collecting spontaneously occurring empirical material (i.e. in its natural setting) as it goes on (i.e. without interference of the structural kind). Such data as, for example, represented by the ordinary conversations occurring between people out there (in the real life), are, according to him, needed in order to complement the present status of our knowledge within the area. That was when I was to ponder the further question as posed in this section: What about the hunter in the picture (i.e. the researcher in relationship to his or her field of inquiry)?
} 
For example, in Moser and Kalton (1986: 270), when reviewing the methods available for collecting information, the authors starts out (in quite a negative way) by stating that interviewing introduces various sources of error and bias, which are then further treated under the heading 'Control and measurement of response errors' (Moser and Kalton 1986: 403). And moreover, from a reasonable fear of influencing the respondent's answer, later adds that 'On no account must the interviewer give an indication of her own views' (Moser and Kalton 1986: 278). However, someone writing from the opposite (such as, say, feminist) quarters might just as well start off by emphasizing - quite to the contrary - the strengths of a mutually interactive perspective. Paradoxically, the more subjective the material becomes in the process of an extended cooperation between the researcher and his/her research subject, the more reliable it also grows.

As a result of such marginalizing tendencies the soft approaches have got a reputation as somehow inferior, despite the fact that they represent an approach that is both time-consuming and demanding of its practitioners. Qualitative methods may paradoxically demand more - not less - than quantitative ones, from the researcher in terms of self-reflection, communicative skills and even ability to endure intimacy (especially with people of different persuasions), the way a maximum utilization of their distinctive character is dependent on a solid theoretical understanding as well as knowledge of the subject theme. In this type of inquiry the researcher is to be used as a participating medium, because it is more loosely structured and dependent upon basic knowledge of the research issues involved, issues on which only the researcher in her/his capacity of an educated observer can best take decisions, and the knowledge of which cannot easily be transformed to another uneducated assistant, at least without proper preparation.

That brings me to the next issue connected with the above difference in scientific outlook, which has, so far, been less considered, but, nevertheless is, in my view, of increasing importance particularly in comparative religion. As an extension of the above-mentioned flexibility demand, it is about the subject-object relationship, while reminding us that such differences also relate to diverse conceptualizations of the role of the researcher in relationship to his research subject (Figure 2). It is the inclusion of contextual factors in the soft method research design, which makes it necessary to take a closer look at the effect of the researcher as well. 


\section{Figure 2}

\begin{tabular}{|ll|}
\hline \multicolumn{2}{|c|}{ Polarities of Subject-Object Interaction } \\
\hline restricted focus/content & flexible/associative content \\
preformulated/-coded & open-ended/informal \\
structured questionnaire & 'conversation with a purpose' \\
subject respondent & subject informant \\
short-term neutral & long-term trustful interaction \\
asymmetrical control/ & closeness/mutuality \\
distance & (dependence) \\
\hline
\end{tabular}

It is especially by way of the post-modernist impulses that the role of the researcher has come under closer scrutiny. Frequently critical voices are heard demanding that the author behind the product be accountable, inquiring about whose history or cultural interpretation, rather than, as the case is in the hard data focus, about the representativity of the research sample. By de-anonymizing the person behind the product one wishes to reach a greater reliability and extend the perspectives that are mediated as truths within the public sphere, not seldom to the benefit of a post-colonial, feminist or microhistorical presentation. Research projects of a kind that may have unforeseen, not seldom political implications, also presuppose the acknowledgment of the vulnerability of the researcher. The said developments have, for example, given rise to intense and, at times, provocative debates about the right of the research subjects to gain insight into research results (and the responsibility of the researcher to see to it) or the power of the powerless - quite often minority groups - to influence what kind of research is done on them; or about the further issue of whether, in the word of the anthropologist Thomas Hylland Eriksen (1997) a professionally good researcher could not simultaneously be immoral as a person, to take just a few examples which have been debated in Norway lately.

Historians of religion have commonly been quite naive when it comes to such problematic aspects of the role of the researcher; as a rule they have been personalized and retold as gossip. In my own career also I have heard many rumors about other colleagues who are supposed to have been accused of being spies while on field work, or they have been exposed in public and charged with racism due to their results, and have had to live under threats of reprisals from 
their own research subjects or foreign regimes, even fearing for their own safety. That is, if they have not been hindered in their pursuits by a variety of so-called gate-keepers by which I mean those who monitor the researcher's access to the empirical material, such as, for example, authorities set to review the use of sensitive or personal data, or some other corporate bodies involved in the issues and/or subjects of one's choice. ${ }^{8}$ In an increasingly bureaucratized world researchers may increasingly (and often rightly so) be dependent on whether they have the formal credentials that may be required for entering the field, such as in my case, for example, as a clinical psychologist in addition to my interest and parallel education in cultural analysis. Renzetti and Lee (1993: 9-10) adds to this picture the issue of legal restrictions that increasingly affect (not only health workers, but) researchers.

What is important here is the fact that this has happened without the information being substantiated or taken seriously as a problem of research. What I ask for is thus an effort to systematize what experiences we have with the vulnerability of the role of the researcher within our subject area. Such backbiting should be brought to light as a problem of method, and the students prepared to handle the mass media, political and other authority figures who may decide on the societal fate of their research findings. I do not mean to say that real conflicts of interest are thereby done away with; my claim is of course more modest, like minimizing the personal pain and problems of public relations that may result from unprepared practitioners in the field, if anyone is to dare thread into the controversial waters that our subject seems so full of.

Instead of attempts at collegial stigmatization on the part of those of us who have been lucky to avoid problems like that (perhaps due to our cowardice?), we should put the issue as such on the agenda in order to prepare us better for real life situations. This is because the problems that may arise in connection with sensitive research are not so much about personal shortcomings or defeat, but, more often than not, about an unintentional politization of research problems and findings, and, above all, about an unfortunate personification of a

${ }^{8}$ For example, in an article entitled "Interviewing Survivors of Marital Rape", Kennedy Bergen (1989) examines how a vast majority of those institutions approached refused her access, from reasons ranging from a plain refusal to acknowledge the occurrence of rape among their clients or protecting them from an overexposure to researchers, to the likelihood of their resisting such a critical scrutiny as a research process is when done by outsiders. 
more general problem. In other instances, this state of affairs may bring self censorship which might render our research and its results innocuous. I think of the lack of studies critical of our main religious denominations (that is, if one excepts studies of societally marginal religious phenomena such as the new religions represent), or as already mentioned within the study of Islam in which case many scholars of our subject have kept silent concerning and/or avoided the more controversial themes. Is there not a risk that we may thereby become toothless?

Putting such issues on the agenda becomes all the more important in the face of the accelerating development that is presently evident within the subject of religious studies as the numbers of students keep rising alongside the increasing interest in religion as a phenomena in the public sphere. A development that poses greater responsibility not merely of how we choose to focus our studies - the ratio between critical as well as understanding perspectives - but also for how we are to prepare for the possible research external utilization of it.

\section{On Context Dependent Data, the Ethics of Research and the Closeness of the Researcher to the Field of Inquiry}

In the efforts to systematize problematic aspects that may arise from sensitive research there is much to gain from inter-disciplinarian cooperation. One thing that I myself have learned while carrying a double role as clinician-psychologist and cultural researcher-field worker, is that, while anthropology has a long experience from fieldwork concerning the subject-object interdependence, it has, nevertheless, shown less systematic efforts at understanding it theoretically. Psychology, on the other hand, has a lot to recommend itself when it comes to instruments for analyzing such dependencies in the form of theories about what are called attributional links and transference or object relations, while it still lacks in cultural sensitivity.

In addition, clinicians largely work through subject-object relations: in psycho-dynamic approaches that is their primary instrument. Moreover, they have the benefit of the closed therapeutic or free exploratory space as it is also designated, which permits in nature experimentation of a kind that offers the flexibility of a qualitative design while it still simultaneously offers a more controllable research situation than what is possible in field work, in which the researcher 
- however unwillingly — is to a much larger extent drawn into the confines of his or her field as envisaged by the so-called arrival stories.

During my project on Kurdish refugees, which was based on yearlong therapeutic contacts, I thus learned a lot about cross-cultural relations (especially, about gender, age or in/out group relations) from the way the clients related to me. Among others things, I learned from their occasional withdrawal behavior, or their viewing the mental health professionals as some kind of extended kin, as well as from their misunderstood expectations about getting help with practical issues. Among the more sensitive factors $I$ - the therapistresearcher - had to confront in this connection, was the refugee research specific danger of retraumatization by way of the reactualization of the traumatic situation during the therapeutic/healing process, which is known, not only to affect the research subjects but the therapist/researcher as well.

Because minority research generally, and that of refugees in particular, touches so heavily upon power relationships - if not criminal victimization (going back to the vulnerable situation of those applying for asylum and their more or less honest brokers and/or hosts) on human atrocity and immense suffering - it becomes especially demanding also for the researcher. Clinicians speak of secondary traumatization or even social stigmatization from the refugee-specific setting, as I would, here, extend to include the researcher's chosen area of investigation. An effect which is seen more clearly within the context of the helping system, which is so to speak expected to remedy the situation. Refugee studies certainly raise a range of problems relating to ethics as well as politics, in addition to the refugee-specific psycho-social setting, which gets reflected also on those who get only indirectly involved.

The methodical starting point for this study of mine was actually in an interdisciplinary challenge coming from the field of cultural studies, and perceived within the mental health care sector, as to where the encounter between helper and patient should take place, and how

${ }^{9}$ Enrique Bustos (1990) has written a highly enlightening article on the splitting mechanisms operating at the organizational level of the professional helping system concerned with refugees as seen in the Nordic setting. And I was once told from a reliable source at the Medical Foundation (a London based center treating torture and Holocaust victims) that when Tuesday was designated as a patient day then every other staff-member was regularly sick on Wednesdays. 
it may affect their relationship. ${ }^{10}$ In order to gain correct information both field worker and therapist make use of systematic emphasizing with the experiences and ways of thinking of persons, who may be very dissimilar to themselves. Neither of them gain from too much closeness and/or distance with their informants but have to alternate between the inside emic and outside etic perspectives. If there is much to learn for psychologists from the cultural sensitivity of the anthropologist, the latter would, however, benefit from the therapeutic insight into the reciprocal impact between the professional and the clients as objects of expectations or attribution in the eyes of each other. ${ }^{11}$

While participating in the lives of their informants, the field worker necessarily becomes a part of his or her field to a much larger extent than is needed within the confines of traditional psychotherapy, the very frames of which are meant to exclude or process such influences by way of the creation of an alternative fictitious stage. By the therapist's refusing extra-therapeutic help (i.e. in the real social world), the whole issue of the cross-cultural disadvantages affecting the patient (which are likely to remain after the particular therapeutic intervention has ended) are instead made explicit, while at the same time the patient's integrity and resourcefulness subsequent to having got the map right, is to a greater extent acknowledged. The curative element is not in persuading the patient, but in the fact that the therapist manages to communicate a correct understanding of the origin and function of the particular problem, as I would add across culture. Regrettably, such basic principles of therapeutic in-

\footnotetext{
${ }^{10}$ The classical problem is that: If the therapist takes part in team-work across professional dividing lines undoubtedly in line with the general interdisciplinary requirements of this field, where there is a particular case (say, of child custody) under scrutiny, a risk of emotional leakage, manipulation and even contamination in the eyes of the patient is impelling. Moreover, for therapists to offer concrete help for problems pertaining to the social welfare or legal sectors may, in addition to the quackery involved from their lack of training, also leave the underlying long-term problems untouched.

${ }^{11}$ For the researcher, that means - in addition to the requirements of writing a research proposal and fund raising - also having to consider what particular kind of person he/she may represent (i.e. public relations or image so to speak) from the point of view of both the research subjects and the gatekeepers surrounding them. And that may apply whether any of them are even conscious of this fact, dependent as it is on what psychology would call the attributional links between researchers and those others whom they depend on for carrying out their work.
} 
teraction are all the more easily lost sight of the greater the religiocultural distance between the therapist and patient becomes.

In addition to ordinary research skills, refugee research frequently requires cultural sensitivity and even political sophistication from its practitioners. This is because it raises a range of sensitive issues that may affect all involved parties, who are at a potential risk from the psychological impact of traumatic material itself, as well as, from its misinterpretation by various interest groups in the society at large. Many important interests may be involved, which make it necessary to consider the research design from the point of view of maximum validity and minimum offensiveness as envisaged by the concept of compassionate scholarship. The researcher does wisely to reckon with the possibility of sanctions from infringement by those in power or by way of somehow incriminating or sensitive material becoming known (cpr. e.g. the harassment of exiled persons by their homeland regimes, or, in the case of asylum seekers, that the empirical data may throw suspicion on their motives as mentioned above).

\section{Summing up}

A main difference between the methodological approaches as referred to in this article - and illustrated by reference to minority studies is in the closeness of the researcher to his field. One could perhaps state that while the researcher draws nearer to his field in soft approaches the theories remain further away from the empirical data (i.e. in that one creates greater vistas) while the opposite is true for those that work with hard data designs, that meta-theories are almost excluded (as pure speculation) due to the strict demands for operationalization, as the (effect of the) researcher is to a greater extend likewise excluded from the picture. Though in both cases the choices made must naturally be made explicit as must the researcher relate to a qualified discussion between experts who have some kind of relationship to the kind of empirical material or theoretical thinking that is at issue in the particular project.

There is professional agreement about the fact that the relationship between empirical facts and theory is problematic, mediated as it is through the work of the researcher and aided by some kind of measurement. Both sides in what has been called a science war accuse each other of renouncing the truth: While the quantitative side claims that qualitative methods merely produce fiction and speculations in the head of the researcher; the qualitative one accuses hard data oriented researchers of loosing themselves in numerical bric-a- 
brac while reminding us of the fact that statistical validation is also dependent on conceptual definitions, is about a certain percentage of something. Numbers without a context remain meaningless.

Before what solutions are sought to this common problem assume widely different forms. While the soft-approach among other things seeks to include the effect of the researcher in the analysis, the hard one, quite to the contrary, wants to exclude it. This is because, unlike a conventional NS or structured intervention which seeks to hold constant the researcher's impact - as it does of all inputs - its unstructured HUM counterpart recognizes the inherent interactiveness or mutual dependence and psychological positioning of the researcher and his or her research subjects, as well as, the wider context it involves. Moreover, in a qualitative approach theories are not considered bare logical apparatuses for prediction, which is why they must not be judged on their predictive power alone, but on the plausibility of the image of the world they help to create (i.e. here the theories function to anticipate reality). Thus even in their capacity of theoreticians - as in that of field workers - researchers are themselves considered involved in the very creation, if not experiencing, of facts. ${ }^{12}$

Again, for those of us who are limited to collecting our own empirical material in interpersonal situations it is moreover important to remember that while the choice of soft methods frequently arises from difficulties in accessibility on the one hand, it may, on the other, bring a range of unwinding problems which result from the increased involvement by the researcher in his or her field of inquiry. This fact reminds us that the subject-object relationship here referred to naturally is not a question of a private but of a professional closeness $\backslash$ distance.

Sensitive research may impinge on all social research (however, not seldom, without the awareness of the involved parties) but it is most evident in demanding research contexts that tend to sharpen ethical dilemmas such as minority and refugee studies. A continued ignoring of the methodological issues inherent in researching sensitive topics would therefore be scientifically regrettable and potentially generate flawed conclusions on which theory, and then public policy, subsequently be built. We must confront theoretically and seriously the problems posed by this, for example, as concerns the role of the researcher discussed in this article. Few subjects would, in my opinion, be better positioned for doing just that than the study of religion.

${ }^{12}$ For a discussion of the processes involved see e.g. Bjerre Nielsen 1995. 


\section{References}

\section{Ahlberg, Nora}

1990 New Challenges - Old strategies. Themes of Variation and Conflict among Pakistani Muslims in Norway. Helsinki: Finnish Anthropological Society. (Transactions of the Finnish Anthropological Association, 25)

1994 Religion, Oppression and the Issue of Human Rights. In: Nils Johan Lavik et al. (eds.), Pain and Survival. Human Rights Violations and Mental Health; pp. 143-177. Oslo: Scandinavian University Press.

1997 "No Five Fingers are alike". What Kurdish Refugee Women told me in a Therapeutic setting. Towards interdisciplinary Theory and Understanding. Oslo: Psychosocial Centre for Refugees. [ms.]

an-Naim, Abdullahi Ahmed

1990 Human Rights in the Muslim World. Socio-Political Conditions and Scriptual Imperatives. A Preliminary Inquiry. Harvard Human Apollon Rights Journal 3: 13-52.

1997 Apollon. Tidsskrift fra Universitetet i Oslo 1. [tema: Fusk i forskningen]

\section{Bergen, Raquel Kennedy}

1993 Interviewing Survivors of Marital Rape: Doing Feminist Research on Sensitive Topics. In: Claire M. Renzetti and Raymond M. Lee (eds.), Researching Sensitive Topics; pp. 197-211. London: Sage.

\section{Bertaux, Daniel}

1991 Biography and Society. The Life Historical Approach in the Social Sciences. Beverly Hills: Sage.

Bjerre Nielsen, Harriet

1995 Seductive Texts with Serious Intentions. Educational Researcher 1995: 4-12.

\section{Bryman, Alan}

1992 Quantity and Quality in Social Research. London: Routledge.

Bustos, Enrique

1990 Dealing with the Unbearable: Reactions of Therapists and Therapeutic Institutions to Survivors of Torture. In: Peter Suefield (ed), Psychology and Torture; pp. 143-63. New York: Hemisphere.

\section{Carli, Amalia}

1997 A Longitudinal Follow-up Study of 13 Argentinean Children adopted to Norway. Their Psychosocial and Legal Situation. Oslo: Psychosocial Centre for Refugees. [research proposal]

\section{Castaneda, Carlos}

1972 A Separate Reality. Further Conversations with Don Juan. New York: Pocket Books.

1974a Journey to Ixtlan. The Lessons of Don Juan. New York: Pocket Books. 1974b Tales of Power. Harmonsworth: Penguin.

1974c The Teachings of Don Juan. A Yaqui Way of Knowledge. New York: Pocket Books. 
1977 The Second Ring of Power. New York: Simon and Schuster.

Clifford, James, and George E. Marcus (eds.)

1986 Writing Culture. The Poetics and Politics of Ethnography. Berekeley: University of California Press.

\section{Geertz Armin W.}

1999 Ethnoheremeneutics in a Postmodern World. In Tore Ahlbäck (ed.), Approaching Religion; vol, 1: pp. 73-86. Åbo: Donner Institute. (Scripta Instituti Donneriani Aboensis, 17: 1)

\section{Harsløf-Hjelde Karin}

1996 Young, Alone and Vulnerable in Exile. On the Psychososcial and Cultural Adaptation of Unaccompanied Minor Refugees. Oslo: Psychosocial Centre for Refugees. [project presentation]

Holter Harriet, and Ragnvald Kalleberg (eds.)

1996 Kvalitative metoder i samfunnsforskning. Oslo: Universitetsforlaget. [2 $2^{\text {nl }}$ ed.]

\section{Hylland Eriksen, Thomas}

1997 Gode forskere - dårlige mennesker. Dagbladet 12.3.

Lawson, Thomas E, and Robert N. McCauley

1990 Rethinking Religion. Connecting Cognition and Culture. Cambridge: Cambridge University Press.

Lindholm, Tore

1992 The Cross-Cultural Legitimacy of Human Rights Prospects for Research. Oslo: Norwegian Institute for Human Rights. (Norwegian Institute for Human Rights. Publication, 3.

\section{Luckmann Thomas}

1999 On the Interpretation of Communicative Processes and the Problem of Religious Language. In Tore Ahlbäck (ed.), Approaching Religion; vol. 1: pp. 151-163. Åbo: Donner Institute. (Scripta Instituti Donneriani Aboensis, 17: 1)

Metcalf, Barbara Daly (ed.)

1996 Making Muslim Space in North America and Europe. Berkeley: University of California Press. (Comparative Studies on Muslim Societies, 22)

Moser Claus, and Graham Kalton

1986 Survey Methods in Social Investigation. Aldershot: Gower.

Pye, Michael

1999 Methodological Integration in the Study of Religions. In Tore Ahlbäck (ed.), Approaching Religion; vol. 1: pp. 181-197. Åbo: Donner Institute. (Scripta Instituti Donneriani Aboensis, 17: 1)

Renzetti, Claire M., and Raymond M. Lee

1993 The Problems of Researching Sensitive Topics In: Claire M. Renzetti and Raymond M. Lee (eds.), Researching Sensitive Topics; pp. 3-13. London: Sage.

\section{Ricoeur, Paul}

1991 Construing and Constructing: A Review of The aims of interpretations by E. D. Hirsch. Chicago: University of Chicago Press, 1976. In: 
Mario J. Valdes (ed), A Ricoeur Reader. Reflection and Imagination. New York: Harvester Wheatsheaf. (Theory/Culture Series, 2)

Shadid, W. A. R., and P. S. van Koningsveld

1991 Blaming the system or blaming the victim? Structural barriers facing Muslims in Western Europe. In: W. A. R. Shadid and P. S. van Koningsveld (eds), The Integration of Islam and Hinduism in Western Europe; pp. 2-21. Kampen: Pharos.

Silverman, David

1989 Qualitative Methodology and Sociology. Describing the Social World. Aldershot: Gower.

Simnes, Audhild, and Therese Nilsen

1997 Religion som faktor i psykologisk behandling. Lestadianismen som et eksempel. Troms $\varnothing$ : Psykologisk Institutt. [presentation of project]

Siöblom, Tom

1999 'Bringing it all back home'. In Tore Ahlbäck (ed.), Approaching Religion; vol. 1: pp. 227-241. Åbo: Donner Institute. (Scripta Instituti Donneriani Aboensis, 17: 1)

\section{Solkal, Alan}

1996 Transgressing the Boundaries: Towards a Transformative Hermeneutics of Quantum Gravity. Social Text 46/47: 217-252.

\section{Syvertsen, Gunmare}

1997 'Publish in a prestigious journal or perish' - publisering i norsk naturvitenskap og medisin. In: Egil Børre Johnsen (ed.), Forbildets forbilder. Oslo: Universitetsforlaget. (Norsk sakprosa, 2)

\section{Thomassen, Einar}

1999 Is Philology Relevant? In Tore Ahlbäck (ed.), Approaching Religion; vol. 1: pp. 243-252. Åbo: Donner Institute. (Scripta Instituti Donneriani Aboensis, 17: 1)

Thorgersen, Layla

1997 A Study of the distribution of Mental Health Problems and Crime among Immigrant Youth in Norway. Oslo: NOVA. [research proposal]

\section{Wiebe, Donald}

1999 Appropriating Religion: Understanding Religion as an Object of Science. In Tore Ahlbäck (ed.), Approaching Religion; vol. 1: pp. 253-272. Åbo: Donner Institute. (Scripta Instituti Donneriani Aboensis, 17: 1)

Yin, Robert $\mathbb{K}$.

1984 Case Study Research. Design and Methods. Beverly Hills: Sage. (Applied Social Research methods Series, 5)] 